\title{
Language in Low-Functioning Children with Autistic Disorder: Differences Between Receptive and Expressive Skills and Concurrent Predictors of Language
}

\author{
Jarymke Maljaars • Ilse Noens $\cdot$ Evert Scholte $\cdot$ \\ Ina van Berckelaer-Onnes
}

Published online: 21 February 2012

(C) The Author(s) 2012. This article is published with open access at Springerlink.com

\begin{abstract}
Language profiles of children with autistic disorder and intellectual disability $(n=36)$ were significantly different from the comparison groups of children with intellectual disability $(n=26)$ and typically developing children $(n=34)$. The group low-functioning children with autistic disorder obtained a higher mean score on expressive than on receptive language, whereas both comparison groups showed the reverse pattern. Nonverbal mental age, joint attention, and symbolic understanding of pictures were analyzed in relation to concurrent receptive and expressive language abilities. In the group with autistic disorder and intellectual disability, symbol understanding and joint attention were most strongly related to language abilities. Nonverbal mental age was the most important predictor of language abilities in the comparison groups.
\end{abstract}

Keywords Autism - Intellectual disability ·

Receptive language . Expressive language .

Joint attention $\cdot$ Symbol understanding

\section{Introduction}

The development of language skills is one of the most important achievements of early childhood. Language acquisition leads to new opportunities in other developmental areas, such as cognitive, social, and emotional

J. Maljaars · E. Scholte · I. van Berckelaer-Onnes

Leiden University, Leiden, The Netherlands

J. Maljaars $(\varangle) \cdot$ I. Noens

Parenting and Special Education Research Unit, Katholieke Universiteit Leuven, Leopold Vanderkelenstraat 32 Bus 3765, 3000 Leuven, Belgium

e-mail: jarymkemaljaars@ @otmail.com development and is a cornerstone for successful outcomes later in life (Schlichting et al. 1995). Although language ability usually develops spontaneously, it does not progress typically for a substantial number of children. Children with autism spectrum disorder (ASD) show impairments in language development (Tager-Flusberg et al. 2005; Eigsti et al. 2011). The development of functional language serves an important prognostic function (Mahwood et al. 2000). Thus, gaining a better understanding of language impairments in ASD is important for development and improvement of interventions.

In order to provide a context in which we can evaluate the language impairments in ASD, typical language development will be described briefly. Bates (1979) indicated two critical transitions in early childhood which precede language development: (1) development of communicative intentionality, and (2) symbol formation. The first transition is the onset of communicative intentionality, when children become aware that their signals influence behavior of others. In typical development, intentionality emerges when children start to use proto-imperative and proto-declarative behaviors, i.e., to obtain a desired object/ event or to share attention/interest between persons on a common focus, by the end of their first year of life (9-13 months) (Baron-Cohen 1989; Bates 1979; Camaioni 1997).

The second transition concerns the emergence of symbol understanding and use. According to Bates (1979) symbol formation requires an understanding of the relationship between a sign and its referent. The sign can replace that referent in a variety of situations, even if the referent is not currently present. During the first years of life children gradually learn to understand and use symbols, which is reflected in the development of conventional gestures, words, and symbolic play (Wetherby et al. 1998). 
Language is a complex symbolic communication system, for which symbol-referent relations cannot be inferred through observations, but have to be learned step by step. Children may use first words before they have any explicit symbolic understanding. Only when a word is generalized beyond the initial learning environment, it may be granted symbol use and understanding (Namy and Waxman 2005). Next to the verbal domain, the process of symbol development can also be examined in the nonverbal domain. Symbolic play requires the ability to symbolize, and awareness of the relation between the present play object or action and its absent referent in daily life (Jarrold et al. 1997). Symbolic play has been linked to language development in typical children and young children with ASD (e.g., Lewis et al. 2000; McCune 1995; Toth et al. 2006). Other symbolic abilities, such as understanding of pictures, have not been studied in relation to language abilities yet. Stephenson and Linfoot (1996) argued that the use of pictures as symbols has clear parallels to the use of words as symbols.

In typical semantic development, language comprehension always precedes production (Fenson et al. 2000a). Word comprehension emerges around 9 months of age and by the first birthday toddlers usually say their first recognizable words. By this age, they can understand many more words and even some simple phrases (Fenson et al. 1994). Initially, meaning is linked to a specific context. Between 12 and 18 months of age, receptive and expressive vocabulary gradually increases and becomes less contextbound (Tager-Flusberg et al. 2009). The production of phrases starts between 18 and 24 months of age (Fenson et al. 1994). During the preschool period, the vocabulary and complexity of grammar expand rapidly (Tager-Flusberg et al. 2005).

Limited intentionality and symbol formation are considered to be core deficits in communication of individuals with ASD (Noens and Van Berckelaer-Onnes 2005; Travis and Sigman 2001; Wetherby et al. 2000). Young children with ASD exhibit intentional communication less frequently than typically developing children or children with developmental delays (e.g., Chiang et al. 2008; Shumway and Wetherby 2009). A reduced amount of intentional communication is also seen in older children with autistic disorder and associated ID (Maljaars et al. 2011). The most striking impairments in ASD are found in proto-declarative communication or joint attention (e.g., Mundy and Burnette 2005). Several studies found a predictive relationship between joint attention and expressive language development for young children with ASD (e.g., Charman et al. 2003; McDuffie et al. 2005; Smith et al. 2007; Watt et al. 2006). Symbolic impairments have already long been associated with ASD (Hammes and Langdel 1981; Ricks and Wing 1975), but it remains unclear whether a more general impairment in symbol formation is related to language impairments in ASD.

Children with ASD vary widely in their language abilities and features. Only a few studies analyzed differences in expressive versus receptive language abilities based on a within-group design (Tager-Flusberg et al. 2005). In toddlers with ASD, lower levels of both expressive and receptive language compared to typical control or norm groups were found. In contrast to typical development, language comprehension is often even more delayed relative to production (Charman et al. 2003; Luyster et al. 2008; Hudry et al. 2010; Weismer et al. 2010). Generally, in older, high-functioning children with ASD the discrepancy between receptive and expressive language decreases (Rapin and Dunn 2003; Tager-Flusberg et al. 2005). Jarrold et al. (1997) described relatively uniform language profiles in children and adolescents with ASD with equal levels of expressive and receptive language. Another study from Kjelgaard and Tager-Flusberg (2001) found that receptive skills were comparable to expressive skills on vocabulary tests.

Research into ASD has focused on high-functioning, rather than low-functioning children with ASD. In case of ASD with co-occurring intellectual disability (ID), children are 'double impaired' with respect to language abilities. A large proportion of low-functioning individuals with ASD do not develop language or acquires at most a few functional words or signs (Boucher et al. 2007; Rapin and Dunn 2003). Language comprehension is always impaired in low-functioning individuals with ASD, although severity varies (Boucher et al. 2007). A higher level of expressive language compared to receptive language can for example be due to echolalia or the ability to label or to reproduce memorized language in specific contexts (Tager-Flusberg et al. 2005). In this way, true level of language understanding is concealed. Not surprisingly, impairments in receptive language are strongly associated with severe behavior problems (Sigafoos 2000). Language abilities and characteristics in children with ASD are closely related to nonverbal cognitive level of functioning (Luyster et al. 2008; Weismer et al. 2010).

Identifying factors that are associated with concurrent language abilities and possibly influence differential outcomes is necessary for improving treatments. General intellectual level of functioning is probably the most important factor associated with language development in children with ASD (Luyster et al. 2008; Weismer et al. 2010), but this factor does not explain all variance in language abilities. Other developmental factors, such as social and cognitive abilities, are also crucial (Thurm et al. 2007; Prizant 1996). Low-functioning children with ASD often exhibit more severe delays in language development relative to their nonverbal cognitive level. The question is 
whether limitations in language abilities in older children with ASD and ID are associated with social aspects, such as the ability to initiate and respond to joint attention, or with cognitive aspects, such as the understanding of symbols. Both limited intentionality and symbol formation are considered to be core deficits in communication development of individuals with ASD (Travis and Sigman 2001). Joint attention cannot be the only explaining factor for language impairment in children with ASD, because older children with ASD sometimes have impaired joint attention skills but adequate levels of language (Bloom 2000). Indirect evidence for an association between symbol formation and language abilities is that individuals with ASD are impaired in their development of different skills that require symbolic abilities, such as language and symbolic play. Furthermore, in contrast with for example specific language impairment, problems in language development seem to be amodal in ASD (Boucher et al. 2007). Nonverbal children with ASD often fail to compensate their lack of verbal communication with other modalities, such as gestures (Mundy et al. 1994). These findings support the hypothesis of a relationship between language development and symbolic capacities in the nonverbal domain.

Research into specific language profiles and the relation with other developmental aspects in low-functioning children with ASD is important from the perspective of clinical practice, but also for research. First, a lack of sufficient functional language can result in challenging behavior, in particular in low-functioning nonverbal individuals (Chiang 2008; McClintock et al. 2003), and form a major stressor for parents (Lecavalier et al. 2006). Language abilities are closely related to later prognosis (Mawhood et al. 2000). Therefore, more insight into developmental factors which are associated with language development in low-functioning children with ASD is important. Better understanding of language impairments in low-functioning children is necessary in order to improve interventions and care. Second, the results can be useful for genetic and neurobiological studies. Individuals with ASD and associated ID are more often included in genetic studies than in behavioral or cognitive studies. Subsetting by language phenotypes has proven to be useful in genetic research, and also led to identification of genome-wide significant loci (Abrahams and Geschwind 2008). Therefore, the main purposes of this study are: (1) to study differences and similarities between receptive and expressive language abilities in children with autistic disorder and ID compared to children with ID without ASD and typically developing children; and (2) to examine whether and how precursors of language (joint attention and symbol understanding) are related to concurrent receptive and expressive language abilities in these groups.

\section{Method}

\section{Participants}

The first group comprised 36 children with autistic disorder and intellectual disability (AD + ID). Participants were included in the $A D+$ ID group if they had received a formal classification of autistic disorder and ID conform DSM-IV-TR criteria (APA 2000) prior to the study. All children had an algorithm score above the threshold for autistic disorder on the Autism Diagnostic Observation Schedule Modules 1 or 2 (ADOS; Gotham et al. 2007) and a classification of autistic disorder on the Diagnostic Interview for Social and Communication Disorders-version 11 (DISCO-11; Wing 2006). Given the classification difficulties in low-functioning individuals, this study focused on the core syndrome instead of the whole spectrum to create a more homogeneous group. Levels of ID ranged from mild to severe (APA 2000), a nonverbal intelligence test confirmed that IQ-scores of all participants were below 70 . The AD + ID group consisted of 32 boys and 4 girls with a mean chronological age of 7.1 years $(S D=2.3$; range: $3.3-11.3)$. The mean nonverbal mental age was 39.0 months $(S D=13.7)$. In some children additional conditions, such as ADHD $(n=3)$, Down syndrome $(n=1)$, and Fragile $\mathrm{X}$ syndrome $(n=1)$, were present. Two comparison groups were used: a group of children with intellectual disability (ID; $n=26$ ) with 15 boys and 11 girls, and a group of young typically developing children (TD; $n=34$ ) with 14 boys and 20 girls. Children in the ID and TD groups did not meet diagnostic criteria for autism spectrum disorder on the ADOS. Children in the ID groups all had a formal classification of ID, ranging from mild to severe (APA 2000), confirmed by a nonverbal intelligence test. The mean chronological age for the ID group was 6.5 years ( $S D=1.5$; range: $4.3-11.0$ ) and for the TD group 3.0 years $(S D=0.5$; range: $1.9-3.9)$. Mean nonverbal mental age for both groups was 38.5 months $(S D=12.7)$ and 4.3 months $(S D=9.5)$, respectively. Additional conditions identified in the ID group were: Down syndrome $(n=11)$, Williams syndrome $(n=1)$, Velo-Cardio-Facial syndrome $(n=1)$, ADHD $(n=1)$, and epilepsy $(n=1)$. The main characteristics of the groups are presented in Table 1.

The AD + ID group and the two comparison groups were comparable with respect to nonverbal mental age $(F(2,93)=0.96, p=0.39)$ (see Table 1$)$, since groups were matched on this variable. There were significant between group differences with respect to chronological age $(F(2,93)=59.46, p<0.001)$, and gender $\left(\chi^{2}(2)=\right.$ 17.71, $p<0.001)$. Logically, post hoc tests revealed that participants in both groups with ID were significantly older than the TD group $(p<0.05)$, because comparable groups 
Table 1 Main characteristics of the subsamples

\begin{tabular}{|c|c|c|c|c|c|c|c|c|c|}
\hline \multirow[t]{2}{*}{ Group } & \multirow[t]{2}{*}{$n$} & \multicolumn{3}{|c|}{ Nonverbal mental age equivalent (in months) } & \multicolumn{3}{|c|}{ Chronological age (in months) } & \multicolumn{2}{|c|}{ Gender (in \%) } \\
\hline & & Range & M & SD & Range & M & SD & Male & Female \\
\hline $\mathrm{AD}+\mathrm{ID}$ & 36 & $<24^{\mathrm{a}}-68$ & 39.0 & 13.71 & $40-136$ & 85.1 & 28.01 & 89 & 11 \\
\hline ID & 26 & $<24^{\mathrm{a}}-63$ & 38.5 & 12.65 & $51-132$ & 78.1 & 17.59 & 58 & 42 \\
\hline TD & 34 & $29-65$ & 42.3 & 9.53 & $23-47$ & 36.5 & 5.97 & 41 & 59 \\
\hline
\end{tabular}

$A D$ autistic disorder, $I D$ intellectual disability, $T D$ typical development

a Minimum score

were created based on level of functioning instead of chronological age. In the $\mathrm{AD}+\mathrm{ID}$ group significantly more males were present than in the two comparison groups. This has not threatened the validity of the study, as there was no difference in language outcomes between boys and girls within the three subsamples $(p>0.05)$.

\section{Instruments}

\section{Language Abilities}

\section{Receptive Language}

Receptive language scores were derived from two different instruments: (a) Reynell test for Dutch language comprehension (Reynell; Van Eldik et al. 1995), or (b) Dutch Communicative Development Inventories-short forms (D-CDI; Zink and Lejaegere 2003). Most language scores were based on the Reynell, which evaluates receptive language between 14 and 75 months. Only for children who did not obtain the basal score ( $<14$ months) on the Reynell (5\% of the participants), D-CDI was used to determine a receptive language score. The Reynell is an adaptation of the Reynell Developmental Language Scales (Reynell 1985); the Dutch adaptation only contains tasks for verbal comprehension. The Reynell has to be administered individually and consists of 87 items concerning comprehension from single words to complex sentences. Because several participants in this study were chronologically older than the normative sample of the receptive and expressive language instruments, age equivalents based on raw scores were used for analyses. The Reynell was found to exhibit good psychometric properties. A good internal consistency $(\alpha>0.80)$ and a sufficient test-retest reliability $(r=0.69)$ were reported. In addition, there were strong correlations between the Reynell scores and chronological age or other language instruments, which supported validity (Van Eldik et al. 1995; Evers et al. 2009). The Dutch adaptation of the MacArthur Communicative Development Inventories (Fenson et al. 2000b), D-CDI list
1 , assesses vocabulary skills between 8 and 16 months of age, based on a parental report. The raw comprehension score was converted into an age equivalent based on percentile 50. The Dutch adaptation of the CDI list 1 has been demonstrated to have very high internal consistency $(\alpha>0.97)$, and a high convergent and sufficient predictive validity (Zink and Lejaegere 2003).

\section{Expressive language}

Language production age equivalents were also derived from two different instruments: (a) Schlichting test for Dutch language production (Schlichting; Schlichting et al. 1995), and (b) Dutch Communicative Development Inventories-short forms (D-CDI; Zink and Lejaegere 2003). The same procedure as for receptive language was used. Children with an expressive language level below 17.5 months (12\% of the participants) were assigned a score based on the D-CDI. The Schlichting measures language production and two different subscales were used: (a) Schlichting vocabulary development (14-75 months), requiring the naming of objects and pictures (62 items), and (b) Schlichting syntax development (21-75 months), assessing sentence structure (40 items). An overall expressive language age equivalent was calculated by averaging vocabulary and syntax age equivalent scores. The psychometric properties of the Schlichting are sufficient to good. The test was found to have a good internal consistency $(\alpha>0.80)$ and adequate test-retest reliability $(r=0.75)$. Correlations between Schlichting scores and other language tests are adequate (Schlichting et al. 1995; Evers et al. 2009). The Dutch CDI list 1, filled out by parents, also evaluates expressive vocabulary (see description above).

\section{Predictors of Language Development}

As explained in the introduction, possible concurrent predictors of language development included in this study were nonverbal mental age, joint attention, and symbolic abilities. 


\section{Non-verbal intelligence}

To measure nonverbal mental age, a Dutch test for nonverbal intelligence, the SON-R $2 \frac{1}{2}-7$ (Tellegen et al. 1998)

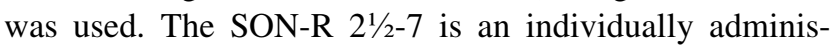
tered measure, which consists of six subtests: three reasoning tests (Categories, Analogies, and Situations) and three spatial, performance tests (Mosaics, Puzzles, and Patterns). Total raw scores were converted into nonverbal mental age equivalents (NVMA). The SON-R 21/2-7 has been found reliable and valid (Evers et al. 2009).

\section{Joint Attention Abilities}

Children's joint attention (JA) abilities were based on ADOS modules 1 or 2 (Lord et al. 1999). The items included were 'Spontaneous Initiation of Joint Attention' (Module 1 item B10 or Module 2 item B6) and 'Response to Joint Attention' (Module 1 item B11 or Module 2 item B7). Initiation of JA codes the child's attempts to draw another person's attention to objects that are out of reach for the purpose of sharing. The item about response to JA addresses the child's response to the examiner's use of gaze and/or pointing to direct the child's attention to a specific object. The raw scores on both items were combined to a total joint attention score.

\section{Symbol Understanding}

Symbol understanding was measured by using an adaptation of different symbolic representation tasks developed by Bebko, McCrimmon and McFee (McFee 2006), based on the procedure of DeLoache and Burns (1994). The adapted version of the dollhouse experiment involves a reduced language protocol and comprises six tasks increasing in difficulty with each task containing six trials. The first three tasks are used to establish understanding of the procedure without the need of verbal instructions by modeling the first item of each task and to practice the search procedure. In task 1 participants had to match identical figurines and in task 2 identical photographs of the figurines were used, which had to be combined with the correct figurine. These two tasks were developed to examine memory and object identification skills, which are necessary for success on the subsequent object-retrieval tasks. The following four tasks consist of search tasks; participants were asked to find a figurine hidden under one of six pieces of household furniture in a 3-floor dollhouse. Photographs of the search location within the dollhouse were shown to the child. The first location searched by the child was recorded as the response. In the 3rd task, the figurine was placed in full view on one of the pieces of furniture, therefore this task can be seen as a training search task. The other three tasks require the participant to use a picture as a symbol. During task 4 , children were shown a photograph of the target item partially visible in its location within the dollhouse, while in the dollhouse the figurine was hidden out of direct view of the child. The 5th task was similar to task 4 with one modification: the photograph did not show the figurine, but only the hiding location. For task 6 the same photographs as for task 5 were used, but the procedure was changed based on the 'HidePicture' condition in the study of DeLoache (1991). In this condition, the children were shown a duplicate figurine and the experimenter positioned the photograph in front of the figurine to give a search instruction (McFee 2006). Tasks 4, 5 , and 6 were used to compose a symbol understanding score, ranging from 0 to 18 based on the sum of correct trials.

\section{Procedure}

Participants were recruited from special schools and day care centers for children with mild to severe ID, and from regular day care centers in the Netherlands. Informed consent from the parents was obtained. Parents were asked to complete the D-CDI questionnaire. Each child was individually tested using the SON-R, Reynell, and Schlichting over the course of three or more sessions at school or day care. The DISCO-11 was administered with one or both parents at home. Thereafter, the child and one of the parents were invited to visit the university, school, or day care of the child, where participants were assessed using the ADOS and the dollhouse experiment.

\section{Data Analyses}

SPSS 18 was used to conduct the analyses. First, receptive and expressive language abilities were evaluated by conducting two analyses of covariance in combination with planned contrasts to compare three subsamples. A repeated measures analysis of covariance (RM-ANCOVA) was used to compare language profiles. Nonverbal mental age was included as covariate in the analyses. Six hierarchical regression analyses were conducted to determine predictors of receptive and expressive language abilities for the separate subsamples. In each analysis, nonverbal mental age was entered in the first step to control for the influence of level of functioning before entering the other predictors. Joint attention and symbol understanding were both entered in the second step, except for joint attention in the TD-group, since the distribution of this variable was too skewed and correlations revealed no significant relationship with language outcomes in this sample. Independent variables were checked for multicollinearity. Correlations between predictors were below $r=0.70$, except for the 
correlation between symbol understanding and NVMA in the AD + ID group $(r=0.75, p<0.001)$ and in the ID group $(r=0.83, p<0.001)$. All other basic assumptions for regression analyses were satisfied. Cases with standardized residuals greater than two standard deviations were excluded from the analyses, but the number of excluded cases did not exceed two per analysis. The variable symbol understanding contained one missing value in the AD + ID group. An alpha level of 0.05 was established throughout all analyses.

\section{Results}

Receptive and Expressive Language Abilities

Although groups were comparable with respect to mean and range of nonverbal mental age, there were significant differences between language abilities of the three groups (Table 2; Fig. 1).

Analyses of covariance with nonverbal mental age as covariate, revealed significant differences between the groups in receptive language $(F(2,92)=31.60, p<0.001$, partial $\left.\eta^{2}=0.41\right)$ and expressive language $(F(2,92)=$ 13.38, $p<0.001$, partial $\eta^{2}=0.23$ ). Based on contrasts, the mean receptive age equivalent of the $\mathrm{AD}+\mathrm{ID}$ group was significantly lower than in the ID group $(p<0.001)$, whereas the ID group scored significantly lower than the TD group $(p=0.02)$. With respect to expressive language there was no difference between the ID groups with and without $\mathrm{AD}(p=0.08)$, but both groups received a significantly lower score than the TD group ( $p s<0.01$ ).

In the $\mathrm{AD}+\mathrm{ID}$ group five children obtained a receptive and expressive language age equivalent below 1;0 year, which means that they did not use or understand any words or at least some simple single words (Table 3). Therefore these children were excluded from the analyses concerning differences between receptive and expressive language levels.

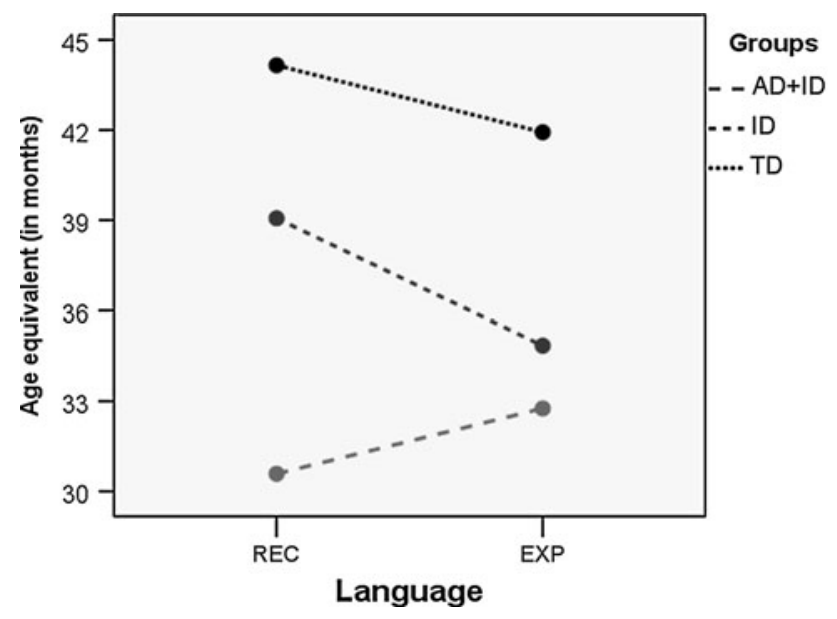

Fig. 1 Language profiles for the three groups

The most striking difference in Table 3 is seen between the $\mathrm{AD}+\mathrm{ID}$ group versus the two comparison groups, $\chi^{2}(4)=14.19, p=0.007$. In the AD + ID group $36 \%$ of the children obtained a higher score on the test for expressive language compared to receptive language, whereas in the ID and TD groups, 54 and 44\%, respectively showed better language comprehension than production skills. In contrast, in the AD + ID group a higher score on receptive language was very uncommon (10\%).

Differences in receptive and expressive age equivalents were further examined using a RM-ANCOVA with nonverbal mental age as covariate (Fig. 1). A significant interaction effect between groups and language abilities was found $\left(F(2,87)=7.64, p=0.001\right.$, partial $\left.\eta^{2}=0.15\right)$, thus language profiles differed among the three groups. Pairwise comparisons revealed that the AD + ID group obtained significantly higher scores on expressive language than on receptive language $(t(30)=-2.65, p=0.013)$, whereas the ID group $(t(25)=2.50, p=0.019)$ and the TD group $(t(33)=2.274, p=0.030)$ showed the opposite profile with significantly higher age equivalents on receptive than on expressive language (Table 2).

Table 2 Language and nonverbal mental age equivalents for each subsample

\begin{tabular}{|c|c|c|c|c|c|c|c|c|c|c|}
\hline \multirow[t]{2}{*}{ Group } & \multirow[t]{2}{*}{$n$} & \multicolumn{3}{|c|}{ Receptive language age equivalent $^{\mathrm{a}}$} & \multicolumn{3}{|c|}{ Expressive language age equivalent $^{\mathrm{a}}$} & \multicolumn{3}{|c|}{ Nonverbal mental age equivalent } \\
\hline & & Range & M & SD & Range & $M$ & $S D$ & Range & M & SD \\
\hline $\mathrm{AD}+\mathrm{ID}$ & 36 & $9-65$ & 27.8 & 14.44 & $8-75$ & 29.4 & 16.85 & $<24^{\mathrm{b}}-68$ & 39.0 & 13.71 \\
\hline ID & 26 & $17-70$ & 37.3 & 12.87 & $13-59$ & 33.1 & 12.78 & $<24^{\mathrm{b}}-63$ & 38.5 & 12.65 \\
\hline TD & 34 & $27-75$ & 45.6 & 11.47 & $23-74$ & 43.3 & 9.92 & $29-65$ & 42.3 & 9.53 \\
\hline
\end{tabular}

$A D$ autistic disorder, $I D$ intellectual disability, $T D$ typical development

${ }^{\text {a }}$ In months

b Minimum score 
Table 3 Cross tab including differences between receptive and expressive language levels

\begin{tabular}{|c|c|c|c|c|c|c|c|c|}
\hline & Difference & $\mathrm{AD}$ & & ID & & $\mathrm{TD}$ & & Total \\
\hline \multirow[t]{2}{*}{$\mathrm{REC}>\mathrm{EXP}$} & $\geq 6$ months & 1 & (3) & 8 & (14) & 8 & (15) & 17 \\
\hline & $\geq 3-5$ months & 2 & & 6 & & 7 & & 15 \\
\hline \multicolumn{2}{|l|}{$\mathrm{REC}=\mathrm{EXP}$} & 17 & & 8 & & 11 & & 36 \\
\hline \multirow[t]{2}{*}{ EXP $>$ REC } & $\geq 3-5$ months & 5 & $(11)$ & 2 & (4) & 6 & (8) & 13 \\
\hline & $\geq 6$ months & 6 & & 2 & & 2 & & 10 \\
\hline \multicolumn{2}{|c|}{ Language levels too low to compare ${ }^{\mathrm{a}}$} & 5 & & 0 & & 0 & & 5 \\
\hline & Total & 36 & & 26 & & 34 & & 96 \\
\hline
\end{tabular}

$A D$ autistic disorder, $I D$ intellectual disability, $T D$ typical development, $R E C$ receptive language, EXP expressive language

${ }^{\mathrm{a}} \mathrm{REC}$ and $\mathrm{EXP} \leq 12$ months

\section{Concurrent Predictors of Receptive and Expressive Language}

Hierarchical regression analyses were performed to explore the relationship between joint attention, symbolic abilities, and level of language comprehension and production in each subsample. Regression analyses were used to control for nonverbal mental age and to assess differences in predictive value of joint attention and symbol understanding. Results of the regression analyses are shown in Table 4.

For the group of low-functioning children with $\mathrm{AD}$, symbol understanding and joint attention were most strongly related to concurrent language abilities. Together, the predictors explained $81 \%$ of the variance in receptive language $(F=41.49 ; p<0.001)$ and $72 \%$ of the variance in expressive language abilities $(F=25.09 ; p<0.001)$. Symbol understanding showed a positive relationship with language abilities and joint attention was inversely correlated with language abilities, since a higher score on joint attention implied more problems with joint attention. With respect to language comprehension, symbol understanding was a stronger predictor $(\beta=0.56)$ than joint attention $(\beta=-0.30)$ (see Table 4).

For the ID group, nonverbal mental age and symbolic abilities were significant predictors for receptive language. These variables accounted for $83 \%$ of the variance. Standardized coefficients showed that nonverbal mental age was the strongest predictor, followed by symbolic abilities. With respect to expressive language in the ID group, and both expressive and receptive language in the TD group, the final model only consisted of nonverbal mental age contributing significantly to the variance (see Table 4).

\section{Discussion}

There is growing interest in studying early language acquisition in toddlers with ASD. Although language is

Table 4 Hierarchical regression analyses for receptive and expressive language including nonverbal mental age, joint attention and symbolic abilities as predictors

\begin{tabular}{|c|c|c|c|c|c|c|c|c|c|}
\hline Group & $n$ & Language & Step & Predictor & Beta & $t$ & $p$ & $R^{2}$ & $p \Delta R^{2}$ \\
\hline \multirow[t]{8}{*}{$\mathrm{AD}+\mathrm{ID}$} & \multirow[t]{4}{*}{33} & \multirow[t]{4}{*}{ Receptive } & 1 & NVMA & 0.73 & 5.94 & $<0.001$ & 0.53 & $<0.001$ \\
\hline & & & \multirow[t]{3}{*}{2} & NVMA & 0.15 & 1.23 & 0.230 & \multirow[t]{3}{*}{0.81} & \multirow[t]{3}{*}{$<0.001$} \\
\hline & & & & JA & -0.30 & -2.68 & 0.012 & & \\
\hline & & & & Symbol & 0.56 & 4.25 & $<0.001$ & & \\
\hline & \multirow[t]{4}{*}{33} & \multirow[t]{4}{*}{ Expressive } & 1 & NVMA & 0.72 & 5.69 & $<0.001$ & \multirow[t]{2}{*}{0.51} & \multirow[t]{2}{*}{$<0.001$} \\
\hline & & & \multirow[t]{3}{*}{2} & NVMA & 0.21 & 1.40 & 0.171 & & \\
\hline & & & & JA & -0.33 & -2.47 & 0.019 & \multirow[t]{2}{*}{0.72} & \multirow[t]{2}{*}{$<0.001$} \\
\hline & & & & Symbol & 0.42 & 2.69 & 0.033 & & \\
\hline \multirow[t]{4}{*}{ ID } & \multirow[t]{3}{*}{25} & \multirow[t]{3}{*}{ Receptive } & 1 & NVMA & 0.89 & 9.25 & $<0.001$ & 0.79 & $<0.001$ \\
\hline & & & \multirow[t]{2}{*}{2} & NVMA & 0.61 & 4.22 & $<0.001$ & \multirow[t]{2}{*}{0.83} & \multirow[t]{2}{*}{0.02} \\
\hline & & & & Symbol & 0.35 & 2.47 & 0.022 & & \\
\hline & 26 & Expressive & 1 & NVMA & 0.84 & 7.65 & $<0.001$ & 0.71 & $<0.001$ \\
\hline \multirow[t]{2}{*}{ TD } & 34 & Receptive & 1 & NVMA & 0.79 & 7.28 & $<0.001$ & 0.62 & $<0.001$ \\
\hline & 33 & Expressive & 1 & NVMA & 0.75 & 6.28 & $<0.001$ & 0.56 & $<0.001$ \\
\hline
\end{tabular}

NVMA nonverbal mental age, JA joint attention, Symbol symbol understanding 
often extremely impaired in older children with ASD and associated intellectual disability (ID), less is known about language profiles and related factors in this low-functioning group with ASD. The first purpose of our study was to examine within- and between-group differences regarding receptive and expressive language in children with autistic disorder (AD) and ID, children with ID without ASD, and typically developing children. Nonverbal mental age was comparable across groups. The second purpose of this study was to examine the contribution of nonverbal cognitive level of functioning and two important precursors of language, joint attention and symbol formation, to concurrent language abilities.

Several key findings emerged from this study of language profiles in low-functioning children with autistic disorder. First, lower scores for both receptive and expressive language were found in the AD group compared to the other groups, while groups scored the same on nonverbal mental age. These results confirm the presence of severe communication problems in low-functioning children with ASD (Noens and Van Berckelaer-Onnes 2004). Second, a substantial discrepancy between expressive and receptive language skills on the one hand and nonverbal cognitive level on the other was found in the group of low-functioning children with autistic disorder. In contrast, in both comparison groups language levels approximated the nonverbal cognitive level, except for expressive language in the ID group. Hence, developmental profiles in low-functioning children with ASD were more uneven than in both comparison groups. Third, language profiles differed significantly across the three groups. Children with AD and ID achieved an expressive language level above their receptive language level, whereas children in the ID and the TD groups showed the opposite profile. However, not in all cases with ASD and ID receptive language was relatively more impaired than expressive language. Approximately half of the group achieved equal levels for receptive as for expressive language, but a substantial part showed a considerably lower level for comprehension than for production. All findings about language profiles are in line with the results for toddlers with ASD (e.g., Hudry et al. 2010; Weismer et al. 2010). However, studies in older high functioning children with ASD found no differences between expressive and receptive language abilities (Jarrold et al. 1997; Kjelgaard and Tager-Flusberg 2001). These previous results, combined with the results of this study, suggest a discrepancy in language profiles between high and low-functioning children with ASD.

The second purpose of this study was to examine the relation between nonverbal mental age, social and symbolic skills with concurrent language abilities. The results suggest that joint attention, symbol understanding, and nonverbal mental age share a substantial amount of variance in the TD and ID groups. However, in the lowfunctioning $\mathrm{AD}$ group other skills made a significant and unique contribution to language outcome. In the TD and ID groups nonverbal mental age was the most robust concurrent predictor of both language comprehension and production. Although nonverbal mental age was correlated with expressive and receptive language skills in the AD group, it did not remain significant in the final regression models, where joint attention and symbol understanding were the major predictors. In general, the role of joint attention in predicting language skills is consistent with previous findings in toddlers with ASD (e.g., Charman et al. 2003; McDuffie et al. 2005). However, the literature reported mixed findings regarding the association between joint attention and language abilities, with several studies indicating joint attention as a stronger predictor for expressive than receptive language (e.g., Watt et al. 2006), but other studies reporting opposite results (e.g., Luyster et al. 2008).

The current data suggest that symbol understanding plays an important role in both expressive and receptive language development in low-functioning children with AD. Nonverbal children with ASD also have difficulties in understanding the symbolic nature of pictures. Therefore, impairments in symbol formation could be a fundamental deficit underlying problems in language development in children with ASD (Bates 1979; Travis and Sigman 2001). The nature of the relationship between joint attention and symbol formation and the relative contribution of both precursors to language development remain unclear. Joint attention is supportive, but not necessary for the acquisition of symbols (Travis and Sigman 2001). On the basis of a longitudinal study in young children with ASD, Toth and colleagues (2006) suggest that joint attention seems to be an important skill for the start of language development, while symbolic play-which refers to more representational or symbolic skills - is associated with the continued development and the expansion of language abilities in later years.

A limitation of our study is the use of different instruments for assessing receptive and expressive language abilities, involving both direct assessment and parent questionnaires. The parental reports were used to correct the floor effects of the direct assessment measures in the lowest functioning children in our study. This strategy was chosen, because several previous studies have suggested that there is a very close agreement among these different language measures (e.g., Fenson et al. 1994; Luyster et al. 2008; Weismer et al. 2010; Zwaigenbaum et al. 2005). No instruments were available which evaluate language comprehension and production for the whole age range of the participants included in this study. The Reynell/Schlichting 
and the D-CDI have the same measurement goal, i.e. assessment of receptive and expressive language, but for a different age range, and all instruments result in an age equivalent score.

The results of our study have clinical relevance with respect to assessment and intervention regarding language abilities in low-functioning children with ASD. Regarding language assessment, our findings indicate that all children with ASD and ID demonstrate significant delays in receptive and expressive language abilities, even relative to their nonverbal cognitive level. Assessment should always include language measurements, in order to elicit strengths and weaknesses so that intervention targets may be adjusted to individual needs. Moreover, both expressive and receptive language abilities need attention separately, because substantial and varying discrepancies might be present. Many low-functioning children with ASD have receptive skills that are more impaired than their expressive language skills. Particularly in the case of more verbal children, communication partners will be misled by the level of expressive language abilities, assuming a comparable level of comprehensions skills (Hudry et al. 2010; Noens and Van Berckelaer-Onnes 2004). In typical development, comprehension always precedes language production. From a developmental perspective, parents, teachers, and caregivers are used to simplifying their language. They often use words and sentence structures just above the expressive language level of children in order to encourage development. Consequently, language comprehension in low-functioning children with ASD is often overestimated, when they are approached at the level of their expressive language (Hudry et al. 2010). Several previous studies demonstrated a significant relation between communication difficulties and the severity of challenging behavior in low-functioning individuals (Bott et al. 1997; Chamberlain et al. 1993; McClintock et al. 2003). The study of Sigafoos (2000) showed that more severe deficits in receptive language compared to expressive language are associated with challenging behavior. Problem behaviors may serve different functions (Day et al. 1994; Hanley et al. 2003; Reese et al. 2005). Some specific behavior problems might be related to receptive communication problems (e.g., to escape too difficult demands) and other to expressive communication problem (e.g., to get a desirable object which is not within reach). Unfortunately, little attention has so far been given to comprehension problems in interventions for children with ASD (Kevan 2003; Sigafoos 2000). Interventions and approaches should have improvement and support of language comprehension as a key target; interventions which only aim for expressive language improvement will widen the gap between comprehension and production. Further, the findings from our study have implications for designing interventions to improve language comprehension. Pictures or objects are often used in a symbolic and representational way to support communication in children with ASD (Wendt 2009). This strategy is problematic when language impairments are accompanied by impairments in symbolic understanding of pictures. For these children, augmentative communication adapted to their level of sense making is a recommended treatment strategy (Noens and Van Berckelaer-Onnes 2004). Facilitating joint attention development is also an important target for intervention in low-functioning children with ASD. Several studies have described techniques that may be effective (e.g. Kasari et al. 2008; Siller and Sigman 2002). Future research will need to examine the relation between symbolic understanding and language development more closely in younger children with ASD, as well as in ASD children with different levels of ID. It is important to differentiate between factors contributing to the emergence and expansion of language skills.

Acknowledgments The authors are grateful to all participants and their families, student, and research assistants who participated in this research. This manuscript was completed in partial fulfillment of the first author's $\mathrm{PhD}$ degree at the Leiden University.

Conflict of interest The authors declare that they have no conflict of interest.

Open Access This article is distributed under the terms of the Creative Commons Attribution License which permits any use, distribution, and reproduction in any medium, provided the original author(s) and the source are credited.

\section{References}

Abrahams, B. S., \& Geschwind, A. (2008). Advances in autism genetics: On the threshold of a new neurobiology. Nature Reviews Genetics, 9, 341-355. doi:10.1038/nrg2346.

American Psychiatric Association (2000). Diagnostic and statistical manual of mental disorders (4th ed.), (text revision). Washington, DC: Author.

Baron-Cohen, S. (1989). Perceptual role-taking and protodeclarative pointing in autism. British Journal of Developmental Psychology, 7, 113-127.

Bates, E. (1979). Intentions, conventions, and symbols. In E. Bates, L. Benigni, I. Bretherton, L. Camaioni, \& V. Volterra (Eds.), The emergence of symbols: Cognition and communication in infancy (pp. 33-68). New York, NY: Academic.

Bloom, P. (2000). How children learn the meaning of words. Cambridge, MA: The MIT Press.

Bott, C., Farmer, R., \& Rohde, J. (1997). Behaviour problems associated with lack of speech in people with learning disabilities. Journal of Intellectual Disability Research, 41, 3-7. doi: 10.1111/j.1365-2788.1997.tb00671.x.

Boucher, J., Mayes, A., \& Bigham, S. (2007). Memory, language and intellectual ability in low-functioning autism. In J. Boucher \& D. Bowler (Eds.), Memory in autism: Theory and evidence (pp. 268-290). Cambridge, UK: Cambridge University Press.

Camaioni, L. (1997). The emergence of intentional communication in ontogeny, phylogeny, and pathology. European Psychologist, 2, 216-225. doi:10.1037/1016-9040.2.3.216. 
Chamberlain, L., Chung, M. C., \& Jenner, L. (1993). Preliminary findings on communication and challenging behaviour in learning difficulty. The British Journal of Developmental Disabilities, 39, 118-125.

Charman, T., Baron-Cohen, S., Swettenham, J., Baird, G., Drew, A., \& Cox, A. (2003). Predicting language outcome in infants with autism and pervasive developmental disorder. International Journal of Language and Communication Disorders, 38, 265-285. doi:10.1080/136820310000104830.

Chiang, H.-M. (2008). Expressive communication of children with autism: The use of challenging behaviour. Journal of Intellectual Disability Research, 52, 966-972. doi:10.1111/j.1365-2788. 2008.01042.x.

Chiang, C.-H., Song, W.-T., Lin, T.-L., \& Rogers, S. J. (2008). Nonverbal communication skills in young children with autism. Journal of Autism and Developmental Disorders, 38, 1898-1906. doi:10.1007/s10803-008-0586-2.

Day, H. M., Horner, R. H., \& O'Neill, R. E. (1994). Multiple functions of problem behaviors: Assessment and intervention. Journal of Applied Behavior Analysis, 27, 279-289. doi: 10.1901/jaba.1994.27-279.

DeLoache, J. S. (1991). Symbolic functioning in very young children: Understanding of pictures and models. Child Development, 62, 736-752. doi:10.1111/j.1467-8624.1991.tb01566.x.

DeLoache, J. S., \& Burns, N. M. (1994). Early understanding of the representational function of pictures. Cognition, 52, 83-110. doi: 10.1016/0010-0277(94)90063-9.

Eigsti, I. M., De Marchena, A. B., Schuh, J. M., \& Kelley, E. (2011). Language acquisition in autism spectrum disorders: A developmental review. Research in Autism Spectrum Disorders, 5, 681-691. doi:10.1016/j.rasd.2010.09.001.

Evers, A., Braak, M. S. L., Frima, R. M., \& Van Vliet-Mulder, J. C. (2009). Commissie Testaangelegenheden Nederland-Documentatie [Committee for Psychometric Evaluation of Psychological Tests of the Dutch Institute of Psychologists-Documentation]. Amsterdam, NL: Boom Test Uitgevers.

Fenson, L., Bates, E., Dale, P., Goodman, J., Steven Reznick, J., \& Thal, D. (2000a). Measuring variability in early child language: Don't shoot the messenger. Child Development, 71, 323-328.

Fenson, L., Dale, P., Reznick, J., Bates, E., Thal, D., \& Pethick, S. (1994). Variability in early communicative development. Monographs of the Society for Research in Child Development, 59, $1-73$.

Fenson, L., Pethick, S., Renda, C., Cox, J. L., Dale, P. S., \& Reznick, J. S. (2000b). Short-form versions of the MacArthur communicative development inventories. Applied Psycholinguistics, 21, 95-116.

Gotham, K., Risi, S., Pickles, A., \& Lord, C. (2007). The Autism Diagnostic Observation Schedule: Revised algorithms for improved diagnostic validity. Journal of Autism and Developmental Disorders, 37, 613-627. doi:10.1007/s10803-006-0280-1.

Hammes, J. G. W., \& Langdel, T. (1981). Precursors of symbol formation and childhood autism. Journal of Autism and Developmental Disorders, 11, 331-346. doi:10.1007/BF01531515.

Hanley, G. P., Iwata, B. A., \& McCord, B. E. (2003). Functional analysis of problem behavior: A review. Journal of Applied Behavior Analysis, 36, 147-185. doi:10.1901/jaba.2003.36-147.

Hudry, K., Leadbitter, K., Temple, K., Slonims, V., McConachie, H., Aldred, C., Howlin, P., Charman, T., \& PACT Consortium. (2010). Preschoolers with autism show greater impairment in receptive compared with expressive language abilities. International Journal of Language and Communication Disorders, 45, 681-690. doi:10.3109/13682820903461493.

Jarrold, C., Boucher, J., \& Russell, J. (1997). Language profiles in children with autism: Theoretical and methodological implications. Autism, 1, 57-76. doi:10.1177/1362361397011007.
Kasari, C., Paparella, T., Freeman, S., \& Jahromi, L. B. (2008). Language outcome in autism: Randomized comparison of joint attention and play interventions. Journal of Consulting and Clinical Psychology, 76, 125-137. doi:10.1037/0022-006X.76.1.125.

Kevan, F. (2003). Link between communication and challenging behaviour. British Journal of Learning Disabilities, 31, 75-80. doi:10.1046/j.1468-3156.2003.00226.x.

Kjelgaard, M. M., \& Tager-Flusberg, H. (2001). An investigation of language impairment in autism: Implications for genetic subgroups. Language and Cognitive Processes, 2001, 287-308. doi: 10.1080/01690960042000058.

Lecavalier, L., Leone, S., \& Wiltz, J. (2006). The impact of behaviour problems on caregiver stress in young people with autism spectrum disorders. Journal of Intellectual Disability Research, 50, 172-183. doi:10.1111/j.1365-2788.2005.00732.x.

Lewis, V., Boucher, J., Lupton, L., \& Watson, S. (2000). Relationships between symbolic play, functional play, verbal and nonverbal ability in young children. International Journal of Language and Communication Disorders, 35, 117-127. doi: 10.1080/136828200247287.

Lord, C., Rutter, M., DiLavore, P. C., \& Risi, S. (1999). Autism diagnostic observation schedule (ADOS). Los Angeles, CA: Western Psychological Services.

Luyster, R. J., Kadlec, M. B., Carter, A., \& Tager-Flusberg, H. (2008). Language assessment and development in toddlers with autism spectrum disorders. Journal of Autism and Developmental Disorders, 38, 1426-1438. doi:10.1007/s10803-007-0510-1.

Maljaars, J., Noens, I., Jansen, R., Scholte, E., \& Van BerckelaerOnnes, I. A. (2011). Intentional communication in nonverbal and verbal low-functioning children with autism. Journal of Communication Disorders,. doi:10.1016/j.jcomdis.2011.07.004.

Mawhood, L., Howlin, P., \& Rutter, M. (2000). Autism and developmental receptive language disorder: A comparative follow-up in early adult life. I: Cognitive and language outcomes. Journal of Child Psychology and Psychiatry, 41, 547-559. doi:10.1111/1469-7610.00642.

McClintock, K., Hall, S., \& Oliver, C. (2003). Risk markers associated with challenging behaviours in people with intellectual disabilities: A meta-analytic study. Journal of Intellectual Disability Research, 47, 405-416. doi:10.1046/j.1365-2788. 2003.00517.x.

McCune, L. (1995). A normative study of representational play in the transition to language. Developmental Psychology, 31, 198-206. doi:10.1037/0012-1649.31.2.198.

McDuffie, A., Yoder, P., \& Stone, W. (2005). Prelinguistic predictors of vocabulary in young children with autism spectrum disorders. Journal of Speech, Language and Hearing Research, 48, 1080-1097. doi:10.1044/1092-4388(2005/075.

McFee, K. H. L. (2006). Understanding the symbolic nature of pictures in children with autism, Master's thesis, York University.

Mundy, P. \& Burnette, C. (2005). Joint attention and neurodevelopment. In F. R. Volkmar, R. Paul, A. Klin, \& D. Cohen (Eds.), Handbook of autism and pervasive developmental disorders. Volume I: Diagnosis, development, neurobiology, and behavior (3rd ed.) (pp. 650-681). Hoboken, NJ: Wiley.

Mundy, P., Sigman, M., \& Kasari, C. (1994). Joint attention, developmental level, and symptom presentation in autism. Development and Psychopathology, 6, 389-401. doi:10.1017/ S0954579400006003.

Namy, L. L., \& Waxman, S. R. (2005). Symbols redefined. In L. L. Namy (Ed.), Symbol use and symbolic representation (pp. 269-277). Mahwah, NJ: Lawrence Erlbaum Associates.

Noens, I., \& Van Berckelaer-Onnes, I. A. (2004). Making sense in a fragmentary world: Communication in people with autism and learning disability. Autism, 8, 197-218. doi:10.1177/1362361 304042723. 
Noens, I., \& Van Berckelaer-Onnes, I. A. (2005). Captured by details: Sense-making, language and communication in autism. Journal of Communication Disorders, 38, 123-141. doi:10.1016/j.jcomdis. 2004.06.002.

Prizant, B. M. (1996). Brief report: Communication, language, social, and emotional development. Journal of Autism and Developmental Disorders, 26, 173-178. doi:10.1007/BF02172007.

Rapin, I., \& Dunn, M. (2003). Update on the language disorders of individuals on the autistic spectrum. Brain and Development, 25 , 166-172. doi:10.1016/S0387-7604(02)00191-2.

Reese, R. M., Richman, D. M., Belmont, J. M., \& Morse, P. (2005). Functional characteristics of disruptive behavior in developmentally disabled children with and without autism. Journal of Autism and Developmental Disorders, 35, 419-428. doi:10.1007/ s10803-005-5032-0.

Reynell, J. K. (1985). Reynell developmental language scales. Windsor, UK: NFER-Nelson.

Ricks, D. M., \& Wing, L. (1975). Language, communication, and the use of symbols in normal and autistic children. Journal of Autism and Childhood Schizophrenia, 5, 191-221. doi:10.1007/ BF01538152.

Schlichting, J. E. P. T., Van Eldik, M. C. M., Spelberg, H. C., Van der Meulen, S., \& Van der Meulen, B. F. (1995). Schlichting test voor taalproductie. [Schlichting test for language production]. Nijmegen, NL: Berkhout.

Shumway, S., \& Wetherby, A. M. (2009). Communicative acts of children with autism spectrum disorders in the second year of life. Journal of Speech, Language, and Hearing Research, 52, 1139-1156. doi:10.1044/1092-4388(2009/07-0280.

Sigafoos, J. (2000). Communication development and aberrant behavior in children with developmental disabilities. Education and Training in Mental Retardation and Developmental Disabilities, 35, 168-176.

Siller, M., \& Sigman, M. (2002). The behaviors of parents of children with autism predict the subsequent development of their children's communication. Journal of Autism and Developmental Disorders, 32, 77-90. doi:10.1023/A:1014884404276.

Smith, V., Mirenda, P., \& Zaidman-Zait, A. (2007). Predictors of expressive vocabulary growth in children with autism. Journal of Speech, Language, and Hearing Research, 50, 149-160. doi: 10.1044/1092-4388(2007/013.

Stephenson, J., \& Linfoot, K. (1996). Pictures as communication symbols for students with severe intellectual disability. Augmentative and Alternative Communication, 12, 244-256. doi: 10.1080/07434619612331277708.

Tager-Flusberg, H., Paul, R., \& Lord, C. (2005). Language and communication in autism. In F. R. Volkmar, R. Paul, A. Klin, \& D. Cohen (Eds.), Handbook of autism and pervasive developmental disorders. Volume I: Diagnosis, development, neurobiology, and behavior (3rd ed.) (pp. 335-364). Hoboken, NJ: Wiley.

Tager-Flusberg, H., Rogers, S., Cooper, J., Landa, R., Lord, C., Paul, R., Rice, M., Stoel-Gammon, C., Wetherby, A., \& Yoder, P. (2009). Defining spoken language benchmarks and selecting measures of expressive language development for young children with autism spectrum disorder.Journal of Speech, Language, and Hearing Research, 52, 643-652. doi:10.1044/ 1092-4388(2009/08-0136).
Tellegen, P. J., Winkel, M., Wijnberg-Williams, B. J., \& Laros, J. A. (1998). Snijders-Oomen Niet-verbale intelligentietest, SON-R 21/2-7: handleiding en verantwoording. [Snijders-Oomen nonverbal intelligence test, SON-R 21/2-7: Manual]. Lisse, NL: Swets \& Zeitlinger.

Thurm, A., Lord, C., Lee, L.-C., \& Newschaffer, C. (2007). Predictors of language acquisition in preschool children with autism spectrum disorders. Journal of Autism and Developmental Disorders, 37, 1721-1734. doi:10.1007/s10803-006-0300-1.

Toth, K., Munson, J., Meltzoff, A. N., \& Dawson, G. (2006). Early predictors of communication development in young children with autism spectrum disorder: Joint attention, imitation, and toy play. Journal of Autism and Developmental Disorders, 36, 993-1005. doi:10.1007/s10803-006-0137-7.

Travis, L. L., \& Sigman, M. (2001). Communicative intentions and symbols in autism: Examining a case of altered development. In J. A. Burack, T. Charman, N. Yirmiya \& P. R. Zelazo (Eds.), The development of autism. Perspectives from theory and research (pp. 279-308). Mahwah, NJ: Erlbaum.

Van Eldik, M. C. M., Schlichting, J. E. P. T., Spelberg, H. C., Van der Meulen, S., \& Van der Meulen, B. F. (1995). Reynell Test voor Taalbegrip. [Reynell test for language comprehension]. Nijmegen, NL: Berkhout.

Watt, N., Wetherby, A., \& Shumway, S. (2006). Prelinguistic predictors of language outcome at 3 years of age. Journal of Speech, Language, and Hearing Research, 49, 1224-1237. doi: 10.1044/1092-4388(2006/088.

Weismer, S. E., Lord, C., \& Esler, A. (2010). Early language patterns of toddlers on the autism spectrum compared to toddlers with developmental delay. Journal of Autism and Developmental Disorders, 40, 1259-1273. doi:10.1007/s10803-010-0983-1.

Wendt, O. (2009). Research on the use of manual signs and graphic symbols in autism spectrum disorders: A systematic review. In P. Mirenda \& T. Iacono (Eds.), Autism spectrum disorders and $A A C$ (pp. 83-117). Baltimore, MD: Brookes.

Wetherby, A. M., Prizant, B. M., \& Schuler, A. L. (2000). Understanding the nature of communication and language impairments. In S. F. Warren, M. E. Frey (Series Eds.), A. M. Wetherby, \& B. M. Prizant (Vol. Eds.), Communication and language intervention series: Volume 9. Autism spectrum disorders: A transactional perspective (pp. 109-141). Baltimore, MD: Paul H. Brookes.

Wetherby, A. M., Reichle, J., \& Pierce, P. L. (1998). The transition to symbolic communication. In A. M. Wetherby, S. F. Warren, \& J. Reichle (Eds.), Transitions in prelinguistic communication. Communication and language intervention series (Vol. 7, pp. 197-230). Baltimore, MD: Brookes.

Wing, L. (2006). Diagnostic interview for social and communication disorders (11th ed.). Bromley, UK: Centre for Social and Communication Disorders.

Zink, I., \& Lejaegere, M. (2003). N-CDI's: korte vormen. [D-CDI's: short forms]. Antwerpen: ACCO.

Zwaigenbaum, L., Bryson, S., Rogers, T., Roberts, W., Brian, J., \& Szatmari, P. (2005). Behavioral manifestations of autism in the first year of life. International Journal of Developmental Neuroscience, 23, 143-152. doi:10.1016/j.ijdevneu.2004.05.001. 